\title{
A trajetória do aprendizado tecnológico nos censos demográfi- cos no Brasil
}

\author{
The technological learning paths of the demographic census in Brazil
}

Paulo Ferreira Vilarinho'

\section{Resumo}

O estudo analisa o desenvolvimento tecnológico do Instituto Brasileiro de Geografia e Estatistica - IBGE, focalizando os projetos censitários, desde sua origem até o advento do Censo Demográfico 2000, tendo por principais fundamentos teóricos os conceitos da acumulação tecnológica (BELL; PAVITT, 1993), associados às competências dinâmicas (TEECE; PISANO; SCHUEN, 1990) e à visão de inovação e aprendizado (DOSI, 1988). A análise dos dados aplica a estrutura analítica de aprendizado e acumulação de competências tecnológicas (FIGUEIREDO, 2001) em níveis gradativos de dificuldade e complexidade, classificando os recursos geradores de inovação e socialização de conhecimentos e seus efeitos nos processos organizacionais. Os dados da pesquisa foram coletados no ano de 2002, por meio de pesquisa documental e entrevistas com funcionários das diretorias técnicas do IBGE.

0 estudo demonstra que o órgão demorou 50 anos para evoluir de um nível básico de experimentação tecnológica, assimilada de países desenvolvidos, até renovar sua tecnologia nos anos 1990, iniciando um processo contínuo e autóctone de geração de conhecimento. Em 2000, logrou alcançar um nível internacionalmente avançado de competência tecnológica passível de exportação. Ao final, o estudo avalia que a visão compartimentada dos órgãos públicos tende a criar "ilhas de especialização" e a não otimizar o uso de tecnologias recém-defasadas.

Palavras-chave: competência tecnológica; Figueiredo; IBGE; censos demográficos;

\begin{abstract}
The study analyses the technological development performed by the Instituto Brasileiro de Geografia e Estatistica (The Brazilian Institute of Geography and Statistics) - IBGE. It focuses on the demographic census from its origins until the census of the year 2000. Its main theoretical basis is the technological accumulation (BELL, PAVIT, 1993) associated with dynamic competences (TEECE; PISANO; SCHUEN, 1990) and innovation and learning theories (G.DOSI, 1988). The empirical basis uses the analytical structure of learning and technological-capability paths (FIGUEIREDO, 2001) to classify the innovation and knowledge socialization resources and its effects on the organization processes. The data were collected through examining documents and making interviews in the boards of technical directors of IBGE in 2002.

The study demonstrates that IBGE has evolved over 50 years from a basic degree of technological experimentation - assimilated from the developed countries - into an international advanced level of technological competence, which was exported in 2000. Finally, this study considers that government institutions' non-integrated understanding tends to establish restricted circles of specialists and not optimizing the use of low depreciated technologies.
\end{abstract}

Key words: technological competencies; Figueiredo; IBGE; demographic census;

${ }^{1}$ Mestre em gestão empresarial pela Escola Brasileira de Administração Pública e de Empresas da Fundação Getulio Vargas - EBAPE/FGV. Doutorando em Saúde Pública na Escola Nacional de Saúde Pública/FIOCRUZ. Endereço: Rua Almirante Cochrane, 236/301, Tijuca - Rio de Janeiro/RJ - Brasil. Email: vilarinho.paulo@gmail.com.

Artigo recebido em julho de 2005 e aceito para publicação em março de 2006. 


\section{Introdução}

Especialmente nas três últimas décadas, com o acirramento da concorrência entre as empresas - estimulada pela integração dos mercados e a abertura das economias emergentes -, muitos estudos focalizaram as causas dos diferentes níveis de capacidade para inovação entre organizações de um mesmo setor da economia. Isso evidenciou profundas discrepâncias quanto à abordagem conceitual entre as literaturas administrativa e econômica, dificultando a construção de um modelo integrado que contemplasse a complexidade da dinâmica interna das organizações e explicasse as causas da sua diferenciação em relação às demais.

Nelson (1991) e Winter (1988) rejeitam o tratamento simplista com que a teoria econômica ortodoxa trata as empresas de um mesmo setor econômico, pois elas são niveladas num lugar-comum e seu comportamento é simulado a partir de modelos hipotéticos configurados em bases irreais. Tais modelos consideram apenas as funções das empresas e sua linha de produtos, da perspectiva da busca incessante do equilíbrio entre oferta e demanda, pela ótica dos preços, o que induz a um mesmo padrão estratégico, direcionado para a maximização do lucro. As abordagens de Nelson (1991) e Winter (1988) integram o ambiente externo com as idiossincrasias internas, tratando as empresas como organismos sociais capazes de experimentar e aprender, consolidando repositórios de conhecimentos específicos do seu negócio.

Particularmente, quanto à tecnologia, por exemplo, enquanto a teoria econômica neoclássica a vê como um insumo cuja eficiência deve ser maximizada, a inovação tecnológica é entendida pela ótica evolucionista como um efetivo fator de diferenciação entre as empresas, que proporciona a prevalência no mercado. Pavitt (1985a) acrescenta que a tecnologia tem natureza cumulativa e tácita, e que o efeito cumulativo decorre do aprendizado consolidado ao longo do tempo e de um contínuo processo de experimentação, o que gera inovações nos modelos teóricos e na prática operacional específicos do negócio da organização. Esses conhecimentos podem estar explícitos, codificados e transcritos em arquivos ou manuais, ou, como é usual, no ambiente subjetivo do corpo técnico, evidenciando-se pelo modo tácito como se apropriam das novas tecnologias e as aplicam na dinâmica operacional da organização.

A tecnologia cria uma rede de interdependência, complementaridade e fatores de indução que impõe às empresas, a setores industriais e mesmo a países, um contínuo alinhamento com modelos paradigmáticos e com a evolução tecnológica, na medida em que coexistem vínculos e influências recíprocas entre distintos grupos de entidades participantes do ambiente de desenvolvimento da tecnologia. Desse modo, a produção de conhecimento deriva da articulação entre centros de pesquisa científica - normalmente, públicos e voltados para a busca de novas bases teóricas nas ciências naturais - com centros privados de inovação tecnológica, detentores de algum conhecimento não disponível. Isso gera uma malha de relacionamentos e um sistema de indução capaz de criar um ambiente de entendimento quanto ao tipo de tecnologia, soluções e práticas a serem adotadas como padrão pelas organizações num dado contexto, numa determinada época (DOSI, 1988).

Por outro lado, Teece (1990) - compartilhando da visão schumpeteriana de Nelson (1991) e Winter (1988), segundo a qual a inovação deriva da experimentação, aprendizagem e adequação, num processo realimentado que se origina na estratégia, mas que também a influencia - avalia que o desempenho de uma organização independe do tipo de estrutura industrial na qual está inserida, não sendo condicionada por fatores externos, mas sim pelos seus valores intrínsecos, como a competência para o desenvolvimento calcada no conhecimento tácito acumulado e, principalmente, pela sua capacidade para o aprendizado. Neste caso, o aprendizado deve ser dinâmico e envolver todo o ambiente da empresa, composto pelo conjunto de forças contrárias ou favoráveis, que podem limitar as opções de oportunidades e investimentos, seja pela inércia provocada pelo conjunto de rotinas históricas já internalizadas na dinâmica operacional da empresa ou por prioridades internas. Portanto, as oportunidades tecnológicas tanto podem representar vetores de convergência como de restrição das escolhas estratégicas da organização, posto que buscam aproveitar as "janelas de oportunidade" e o timing para a execução da ação estratégica, com vistas à adoção de inovações nos seus produtos. 
Bell e Pavitt (1993), por sua vez, consideram que existe uma diferenciação, cada vez mais evidente, entre o tipo de conhecimento e as habilidades necessárias à operação de sistemas de produção e os requisitos para transformá-los. Essas duas competências demandam níveis distintos de investimento na capacitação de recursos humanos, tanto para "receber e usar" novas tecnologias e sistemas de produção, quanto "para mudar" esses sistemas, adequando-os às circunstâncias da organização, desenvolvendo, inclusive, inovações sobre projetos originais.

Os autores definem a competência tecnológica como um conjunto de recursos de natureza intangível, na forma de conhecimentos e habilidades específicas, necessários à geração e gestão de mudanças técnicas. Esse tipo de competência identifica a capacidade de produção da organização num ambiente caracterizado, cada vez mais, pela descontinuidade tecnológica e pelo crescente investimento em conhecimento intensivo.

Particularmente, no caso de empresas situadas em países emergentes, estas precisam acumular suas próprias competências tecnológicas, pelo fato de que o desenvolvimento da produção é acompanhado de significativa acumulação tecnológica, que reúne um forte componente de conhecimento tácito, tornando muito lenta, imprecisa e onerosa a sua transferência de países industrializados para aqueles em desenvolvimento. As capacidades para desenvolver, usar e mudar tecnologias são tidas como praticamente impossíveis de serem transferidas, razão pela qual os países em desenvolvimento devem acumular competências próprias ${ }^{2}$ para que, uma vez importada uma avançada tecnologia, saiba incorporá-la ao nível tecnológico de sua indústria, criar habilidades e conhecimentos e desenvolver implementos e novas tecnologias a partir da original importada.

A pesquisa, desenvolvida em 2002, pretende identificar a estratégia de acumulação de competências tecnológicas para o projeto dos censos demográficos do Brasil, realizado pelo IBGE, com base em dados documentais e em entrevistas com o corpo técnico da diretoria de informática (DI) e da coordenação do censo demográfico (CCD) do instituto, analisados ao longo do tempo, com cortes na descontinuidade tecnológica.

\section{Os censos demográficos no Brasil e a criação do IBGE}

A história dos recenseamentos gerais do Brasil é tão tortuosa e cheia de dificuldades quanto à do próprio país, o que se reflete no desenvolvimento da tecnologia aplicada nesses projetos. De início, a partir de 1750, com objetivos estritamente militares, a coroa portuguesa realizava, de forma direta, levantamentos da população livre e adulta, apta a ser convocada para a defesa do território. Posteriormente, os serviços estatísticos oficiais coletavam os dados de modo indireto, ou seja, estes não resultavam de apurações para contagem do número de habitantes. Os dados eram tirados de relatórios elaborados para outras finalidades, como o das autoridades eclesiásticas sobre os fiéis freqüentadores das igrejas e o das autoridades públicas sobre os funcionários da colônia, aos quais também eram agregadas estimativas fornecidas pelos ouvidores e outras autoridades à Intendência Geral da Polícia. Consolidando dados de diferentes fontes, foi concluído, em 1872, o primeiro levantamento censitário do país, o Recenseamento da População do Império do Brasil, que somou um contingente de 9.930 .478 habitantes (HIPPÓLITO, 1990).

Com o advento da República, as atividades censitárias foram consideradas um dever oficial do Estado, pois ficou decidido que os membros da Câmara dos Deputados seriam eleitos pelo voto proporcional, ordenamento jurídico3 que tornou indispensável a contagem criteriosa da população, para servir de base à distribuição das cadeiras na Câmara. Mesmo assim, os trabalhos do Censo Demográfico da República, de 1890, foram extremamente lentos, arrastando-se por cinco anos após a realização da coleta. Seus resultados só foram oficialmente divulgados na véspera do censo de 1900, portanto com 10 anos de atraso, no primeiro Anuário Estatísti-

\footnotetext{
${ }^{2}$ Segundo Pavitt (p.vii-ix, 1985), "a formação do conhecimento técnico inclui entendimentos imperfeitos, avaliações incompletas, imitações imperfeitas e outros componentes tácitos; fatores que impedem a transferência automática de tecnologia. O sucesso da aplicação de novas tecnologias tende a ser dependente de firmas e países que desenvolvem suas próprias competências".
}

${ }^{3}$ Decreto $\mathrm{n}^{\circ} 510$, de 22-6-1890. 
co do Brasil, registrando 14.433.915 habitantes e caracterizado por forte inconsistência metodológica, além da desobrigação constitucional de cooperação entre os Estados e a União (HIPPÓLITO, 1990).

A criação do IBGE, em 1936, ${ }^{4}$ ocorreu num contexto de forte centralização política em torno do Estado, para um Brasil uno e integrado - sem a compartimentação institucionalizada na "Velha República" -, com um Poder Executivo forte e apto para conduzir a economia a novos patamares, seguindo o modelo de substituição das importações e de incremento do mercado interno. Em 1937, o governo Vargas derrubou as barreiras alfandegárias, queimou em cerimônia pública, no Rio de Janeiro, as bandeiras estaduais e brandiu o dístico: "Grande, só o Brasil !" (PENHA, 1993, p.65)

A centralização política na gestão do território nacional foi um dos traços marcantes do Estado Novo. Ao IBGE coube um papel relevante nesse mister, sendo instituído como órgão consultivo, deliberativo e executivo, subordinado diretamente à Presidência da República, com atividades atreladas às metas governamentais de interiorização do país, de racionalização administrativa, de incremento do mercado interno e difusão da ideologia nacionalista. Suas atribuições principais consistiam em:

- realizar levantamentos, sistematizando os dados do quadro territorial nos aspectos físico, econômico, jurídico, político e populacional;

- levantar a cartografia em variadas escalas;

- divulgar a cultura geográfica brasileira;

- reorganizar o quadro de unidades político-administrativas; e

- definir os limites e racionalizar a toponímia dos municípios e distritos, para estabelecer uma nova divisão territorial.

Não resolver essas questões poderia comprometer a administração pública sob vários aspectos, principalmente quanto à divisão de tributos e verbas orçamentárias, à regularização de áreas rurais e urbanas, aos pleitos eleitorais e aos conflitos decorrentes da repartição do poder político entre as elites locais. Nesse sentido, o estabelecimento de um sistema geográfico-estatístico padronizado propiciou um entrosamento racional e a progressiva adaptação dos órgãos técnicos existentes no âmbito das administrações federais, estaduais e municipais, as quais, por estarem até então submetidas às jurisdições regionais e locais, tendiam a ficar desconectadas dos objetivos nacionais.

Nesse contexto, o forte movimento de urbanização e industrialização do país nas décadas de 1930 e 1940, seguido pelo "desenvolvimentismo" dos anos 1950, integrando diferentes regiões econômicas, demandou um conhecimento mais preciso do território nacional, como base para a formulação de estratégias de integração socioespacial, nas quais o governo exerceu importante papel condutor.

No final dos anos 1980, o contexto de redemocratização do país estimulou que o IBGE - até então um órgão autônomo e fechado, responsável pela estatística, geografia e cartografia do Brasil - buscasse se integrar aos novos paradigmas sociais, conforme indicado em fóruns públicos de discussão, modernizando-se para o censo de 1991 e dando início à renovação da tecnologia e rotinas organizacionais, praticamente estagnadas por quase 40 anos, fortalecendo as bases de uma crescente e autóctone trajetória de aprendizagem tecnológica e de contínuo aprimoramento. Esses fatores culminaram no Censo Demográfico 2000, notabilizado pela rapidez na di-

\footnotetext{
${ }^{4}$ A data oficial de criação do IBGE é 29-5-1936, com o Instituto Nacional de Estatística, extinto em 26-1-1938, compondo o Conselho Nacional de Estatística, em 17-11-1936, o Conselho Nacional de Geografia, em 24-3-1937, e a Comissão Censitária Nacional, em 2-21938.

${ }^{5}$ A promulgação da Constituição Federal de 5-10-1988 e a Nova República;
} 
vulgação e na qualidade dos dados referentes à realidade física e social do Brasil, resultando na exportação de conhecimento tecnológico.

\section{As taxonomias de acumulação de competências tecnológicas}

Ao focalizarem a questão da geração de competências tecnológicas em empresas atuantes em países emergentes, muitos pesquisadores (BELL; PAVITT, 1993; FIGUEIREDO, 2001; LALL, 1992; LEONARD-BARTON, 1998) desenvolveram taxonomias que se complementam na categorização dos diversos níveis de complexidade alcançados ao longo do tempo.

- A classificação de Lall (1992) associa duas funções básicas, o investimento e a produção, em três níveis de complexidade:

- básico - relacionado com a absorção de rotinas operacionais;

- intermediário - sobre o grau de competência para efetuar adaptações nas rotinas; e

- avançado - quando a empresa acumula capacidade para desenvolver inovações tecnológicas.

Por sua vez, Bell e Pavitt (1993), reportando-se a Lall (1992), prescrevem uma trajetória de acumulação em etapas de gradativa complexidade, ao longo das quais as empresas iniciantes concentram investimentos na exploração de tecnologias já maduras, elevando continuamente seus níveis de produtividade pelos baixos custos e as melhorias oriundas do aprendizado experimental, segundo o modelo learnig by doing, até alcançarem um nível de competência que as habilite a desenvolver inovações.

Figueiredo (2001, p.28) - desagregando a taxonomia de Bell e Pavitt (1993) - incorpora novos conceitos, distinguindo níveis secundários de complexidade, tanto no âmbito das rotinas como no das inovações. Para isso, o pesquisador desenvolve uma matriz, associando quatro funções tecnológicas (e atividades decorrentes), com sete níveis de complexidade, apontando as competências vinculadas às rotinas e às inovações, tal como apresentado na tabela 1.

Cabe alertar que para os objetivos deste estudo, foram feitas algumas poucas adaptações nas descrições dos campos da tabela original da taxonomia de Figueiredo (2001), visando torná-la mais genérica e a facilitar sua aplicação ao caso dos censos demográficos do IBGE. Na obra original, Figueiredo (2001, p.28) recorre a um exemplo extraído da indústria metalúrgica. 
Tabela 1

Competências tecnológicas em organizações em países em desenvolvimento

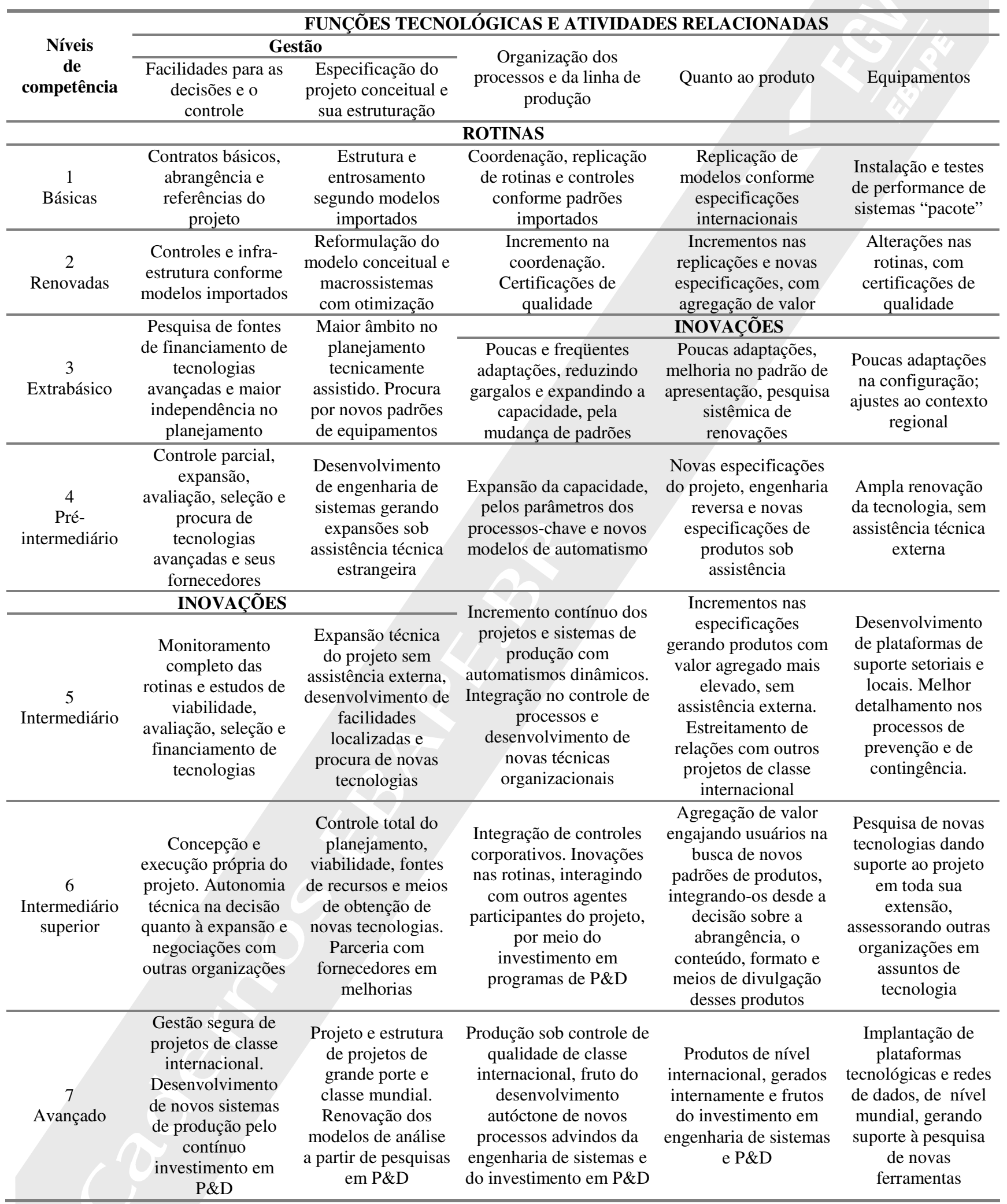

Fonte: adaptado de Figueiredo (2001, p.37). 
Figueiredo (2001) decompõe a aprendizagem em processos de conversão de conhecimentos e de aquisição e, estes, por sua vez, nas modalidades externa e interna. Os processos de conversão são também desmembrados em níveis secundários: processos de socialização e de codificação de conhecimentos tácitos. A estrutura, como um todo, envolve quatro processos de aprendizagem com diferentes subprocessos e mecanismos, como disposto no quadro 1.

\section{Quadro 1}

Principais características dos processos de aprendizagem

\begin{tabular}{|c|c|c|c|c|}
\hline \multirow{3}{*}{$\begin{array}{l}\text { Processos de } \\
\text { aprendizagem }\end{array}$} & \multicolumn{4}{|c|}{ CARACTERÍSTICAS-CHAVE DOS PROCESSOS DE APRENDIZAGEM } \\
\hline & Variedade & Intensidade & Funcionamento & Interação \\
\hline & $\begin{array}{c}\text { Ausência/presença } \\
\text { Limitada-moderada- } \\
\text { diversa }\end{array}$ & $\begin{array}{l}\text { Única-intermitente- } \\
\text { contínua }\end{array}$ & $\begin{array}{l}\text { Pobre-moderado-bom- } \\
\text { excelente }\end{array}$ & Fraca-moderada-forte \\
\hline \multicolumn{5}{|c|}{ Processos e mecanismos de aquisição de conhecimento } \\
\hline $\begin{array}{c}\text { Aquisição } \\
\text { externa de } \\
\text { conhecimento }\end{array}$ & $\begin{array}{c}\text { Presença/ausência de } \\
\text { processos para } \\
\text { aquisição de } \\
\text { conhecimentos no local } \\
\text { ou no exterior. Diversas } \\
\text { maneiras de trazer } \\
\text { distintos tipos de } \\
\text { conhecimento } \\
\text { especializado para a } \\
\text { organização }\end{array}$ & $\begin{array}{c}\text { O modo como a } \\
\text { organização faz uso } \\
\text { desse processo pode ser } \\
\text { contínuo, intermitente ou } \\
\text { ocorrer apenas uma } \\
\text { única vez, de forma } \\
\text { isolada }\end{array}$ & $\begin{array}{l}\text { Como o processo é criado e } \\
\text { atua ao longo do tempo, } \\
\text { tanto pode fortalecer quanto } \\
\text { mitigar a variedade e } \\
\text { intensidade da aquisição do } \\
\text { conhecimento. Tempo: } \\
\text { "aprender antes de fazer" }\end{array}$ & $\begin{array}{l}\text { O modo como o processo } \\
\text { influencia outros } \\
\text { processos de aquisição de } \\
\text { conhecimento de origem } \\
\text { externa e interna e/ou } \\
\text { outros processos de } \\
\text { conversão de } \\
\text { conhecimentos }\end{array}$ \\
\hline $\begin{array}{l}\text { Aquisição } \\
\text { interna de } \\
\text { conhecimento }\end{array}$ & $\begin{array}{c}\text { Presença/ausência de } \\
\text { processos para } \\
\text { aquisição de } \\
\text { conhecimentos por } \\
\text { meio de atividades } \\
\text { internas (by doing), que } \\
\text { podem ser por rotinas } \\
\text { operacionais ou } \\
\text { atividades inovadoras }\end{array}$ & $\begin{array}{c}\text { Como a organização } \\
\text { utiliza os variados } \\
\text { processos internos de } \\
\text { aquisição de } \\
\text { conhecimento, podendo } \\
\text { influenciar os indivíduos } \\
\text { na compreensão dos } \\
\text { princípios envolvidos na } \\
\text { tecnologia }\end{array}$ & $\begin{array}{l}\text { O modo como o processo é } \\
\text { criado e como ele atua ao } \\
\text { longo do tempo tem } \\
\text { implicações práticas na } \\
\text { variedade e intensidade. } \\
\text { Tempo: "aprender antes de } \\
\text { fazer" }\end{array}$ & $\begin{array}{c}\text { A aquisição de } \\
\text { conhecimento interna } \\
\text { pode começar pelo } \\
\text { processo de aquisição } \\
\text { externa de } \\
\text { conhecimentos, os quais } \\
\text { também podem acionar } \\
\text { processos internos de } \\
\text { conversão de } \\
\text { conhecimento }\end{array}$ \\
\hline \multicolumn{5}{|c|}{ Processos e mecanismos de conversão de conhecimento } \\
\hline $\begin{array}{l}\text { Socialização de } \\
\text { conhecimentos }\end{array}$ & $\begin{array}{l}\text { Presença/ausência de } \\
\text { diferentes processos } \\
\text { pelos quais indivíduos } \\
\text { compartilham seu } \\
\text { conhecimento tácito }\end{array}$ & $\begin{array}{c}\text { O modo como os } \\
\text { processos perduram ao } \\
\text { longo do tempo. Uma } \\
\text { intensidade contínua de } \\
\text { socialização de } \\
\text { conhecimentos pode dar } \\
\text { início à codificação de } \\
\text { conhecimentos }\end{array}$ & $\begin{array}{c}\text { O modo como os } \\
\text { mecanismos de socialização } \\
\text { de conhecimentos são } \\
\text { criados e operam ao longo } \\
\text { do tempo tem implicações } \\
\text { na variedade e intensidade } \\
\text { do processo de conversão } \\
\text { de conhecimentos }\end{array}$ & $\begin{array}{c}\text { Trazer diferentes } \\
\text { conhecimentos tácitos } \\
\text { para um sistema em } \\
\text { operação, com links entre } \\
\text { tipos diferentes de } \\
\text { conhecimentos. A } \\
\text { socialização pode ser } \\
\text { influenciada por } \\
\text { processos de aquisição } \\
\text { externos e internos }\end{array}$ \\
\hline $\begin{array}{l}\text { Codificação de } \\
\text { conhecimentos }\end{array}$ & $\begin{array}{l}\text { Presença/ausência de } \\
\text { diferentes processos e } \\
\text { mecanismos voltados } \\
\text { para a codificação de } \\
\text { conhecimentos tácitos }\end{array}$ & $\begin{array}{l}\text { O modo como processos, } \\
\text { como os de } \\
\text { padronização, são } \\
\text { repetidamente realizados. } \\
\text { A codificação ausente ou } \\
\text { intermitente pode limitar } \\
\text { o aprendizado } \\
\text { organizacional }\end{array}$ & $\begin{array}{l}\text { O modo como os processos } \\
\text { de codificação são criados e } \\
\text { operam ao longo do tempo } \\
\text { atuam na conversão de } \\
\text { conhecimentos, e também } \\
\text { na variedade e intensidade } \\
\text { desse processo }\end{array}$ & $\begin{array}{c}\text { O modo como a } \\
\text { codificação de } \\
\text { conhecimentos é } \\
\text { influenciada pelos } \\
\text { processos de aquisição de } \\
\text { conhecimentos ou por } \\
\text { outros processos de } \\
\text { socialização de } \\
\text { conhecimentos }\end{array}$ \\
\hline
\end{tabular}

Fonte: Figueiredo (2001, p.37). 


\section{A trajetória da acumulação de competências tecnológicas dos censos demográficos}

Historicamente, pela sua magnitude, a cada decênio, os censos demográficos estimulam saltos de qualidade no ambiente tecnológico do IBGE. É quando novos recursos e modelos de gestão são experimentados e posteriormente incorporados aos processos das pesquisas estatísticas mensais. Isso estabelece um fluxo de transferência interna dos conhecimentos adquiridos nas operações censitárias para as atividades rotineiras, melhorando-as, ou seja, confirmando o efeito cumulativo da tecnologia apreendida ao longo do tempo, num contínuo processo de experimentação e aprendizado (PAVITT, 1985).

O censo demográfico de 1980 foi o último no qual o processamento se baseou no modelo tradicional de centralização física e operacional das rotinas de digitalização de questionários e de crítica de consistência. Os altos custos da contratação externa de mão-de-obra digitadora, de equipamentos e do armazenamento de material, além de um rígido controle de qualidade e da produção, contribuíram para esgotar esse modelo em meados daquela década. Em linhas gerais, a tecnologia usada no CD-1980 consistia em uma rede de terminais IBM interligados a um main frame, ${ }^{6}$ com cerca de 4.000 digitadores alocados num processo de digitação manual, revezados em vários turnos, concentrados em galpões no Rio de Janeiro.

A rotina de crítica rejeitava todo o questionário ao sinal de qualquer incoerência num único campo de resposta. $\mathrm{Na}$ fase de coleta, os questionários, depois de aplicados à população em todo o território nacional, eram aferidos quanto à quantidade, empacotados por lotes e levados em caminhões até a sede, no Rio de Janeiro, quando eram conferidos, digitados e tabulados para a crítica de consistência dos agregados estatísticos, gerando volumosos expurgos da base de dados. Por fim, era processada a análise estatística, os cortes em grupamentos de variáveis, os cálculos de correlações e inúmeras inferências de natureza exploratória.

No censo de 1990, utilizando tecnologia de mini e microcomputadores de alta capacidade, as etapas iniciais da apuração da coleta de dados foram transferidas para as unidades regionais e estaduais, descentralizando-se definitivamente uma estrutura operacional até então concentrada na sede. Em todas as unidades regionais do IBGE foram implantados ambientes tecnológicos, o que possibilitou a capacitação local do corpo técnico em sistemas de informática e gestão de processos, seguindo uma metodologia uniforme e estimulando a crítica e o aprimoramento local de rotinas organizacionais que foram incorporadas no contexto do projeto. Uma vez digitados, criticados e tabulados in loco, os dados eram transmitidos por linhas transdata ao main frame, na sede, que apenas processava a crítica de consistência e a análise estatística propriamente dita.

Assim, por um processo de indução, do pólo tecnicamente desenvolvido do Rio de Janeiro para as unidades do interior do país, estabeleceu-se um ambiente de entendimento recíproco que resultou em soluções práticas conseguidas a partir da ocorrência de problemas, onde quer que surgissem, as quais, depois, eram naturalmente incorporadas aos processos da organização (DOSI, 1988). A partir dessa época, foi intensificada a ida de técnicos para aprimoramento no exterior, em cursos de doutorado em demografia e estatística nos EUA, além de prolongados estágios na sede do Bureau of Census, órgão estatístico do governo norte-americano.

Em 1996, a recém-surgida tecnologia das leitoras óticas foi experimentada com sucesso no projeto-piloto da contagem populacional, para transcrição direta dos questionários, embora, por precaução, as tradicionais operações de digitação tenham sido mantidas nas demais pesquisas.

A experiência acumulada norteou adaptações nos equipamentos óticos, elevando o grau de sensibilidade do reconhecimento ótico e determinando a sua utilização no censo de 2000. Optou-se pela tecnologia de digitalização de imagens, em face do desenvolvimento dos scanners, das mídias de processamento de imagens e de reconhecimento de marcas, de caracteres alfanuméricos impressos e manuscritos. A inovação advinda da experimentação gerou um tipo de aprendizagem que influenciou a formulação da estratégia global do projeto, num

${ }^{6}$ Processador IBM 9.021, modelo 620, quadriprocessador com 192MB de memória central e 1.024MB de memória expandida. 
processo recursivo dinâmico (TEECE et al, 1990) que resultou na expansão da capacidade operacional e no incremento da sua eficiência, como mostrado na tabela 2, de comparação entre os censos.

Tabela 2

Comparações entre recursos tecnológicos aplicados nos censos

\begin{tabular}{cccc}
\hline & CD-1980/81 & CD-1990 & CD-2000 \\
\hline № de questionários & 34 milhões & 40 milhões & 46 milhões \\
\hline $\begin{array}{c}\mathbf{N}^{\mathbf{0}} \text { de protótipos } \\
\text { No recenseadores } \\
\text { contratados }\end{array}$ & - & - & 2 \\
\hline $\mathbf{N}^{\mathbf{0}}$ de digitadores & $150 \mathrm{mil}$ & $180 \mathrm{mil}$ & 215 mil \\
\hline $\begin{array}{c}\text { Repasses financeiros diretos } \\
\text { (R\$) }\end{array}$ & 480 milhões & $2,5 \mathrm{mil}$ & - \\
\hline $\begin{array}{c}\text { Tempo de apuração do } \\
\text { projeto }\end{array}$ & 60 meses & 580 milhões & 560 milhões \\
\hline Transporte de questionários & Caminhões & 24 meses & 6 meses \\
\hline $\begin{array}{c}\text { Tecnologia de transcrição de } \\
\text { dados }\end{array}$ & Digitação centralizada & Digitação descentralizada & $\begin{array}{c}\text { Transcrição e } \\
\text { identificação automática }\end{array}$ \\
\hline
\end{tabular}

Fonte: IBGE/DI-CCD.

* valores atualizados até 2000 .

A escolha da tecnologia de digitalização de imagens, usada no CD-2000, exigiu um processo de aquisição de conhecimento externo, na medida em que esse processo, inédito no Brasil, estava em fase de aplicação experimental nos EUA e na Turquia e, ainda, em estudos na Argentina e no Uruguai.

O grau de inovação desse processo exigiu o envio de técnicos da diretoria de informática aos EUA, em visitas ao Bureau of Census, em Suitland, no Estado de Maryland, e à unidade da Receita Federal, Department of Treasury, em Boston, Massachusetts. No Bureau of Census foi avaliado o ambiente físico dos centros de captura de dados, destinadas à digitalização de imagens dos questionários, mas ainda em fase de experimentação. Na Receita Federal, foi avaliada a mesma tecnologia quanto ao preparo dos documentos e o fluxo das etapas e equipamentos, além dos cuidados exigidos para o reconhecimento dos caracteres a serem digitalizados, assim como o modelo de armazenamento dos dados.

Desse modo, a incerteza e os riscos inerentes à aplicação de uma tecnologia inovadora num projeto de grande magnitude induziram ao investimento na busca comparativa de experiências já iniciadas em outros centros governamentais de pesquisa (DOSI, 1988), determinando a opção pela tecnologia dos scanners, associada a sistemas de identificação de caracteres que deveriam ser customizados às características da grafia dos recenseadores brasileiros.

O aprendizado acumulado no CD-2000 foi bastante abrangente. Na área técnica, por exemplo, visando à segurança, a testes e revisões nos sistemas, foram implantados dois protótipos em regiões com características demográficas bem distintas, para simular a heterogeneidade da população brasileira: nas cidades de Marília, em São Paulo, e Bonito, no Pará. Com base na experiência adquirida nos protótipos, foram desenvolvidas inúmeras adequações no produto israelense de reconhecimento automático de caracteres, marcas óticas e códigos de barra, agregando 1.000 homens/hora de trabalho de análise e programação de sistemas.

Para avaliar a extensão do planejamento, foram feitas visitas à China, para estudo do modelo adotado para um censo cuja magnitude alcança 150 milhões de recenseadores para aplicação de questionários a 1,5 bilhões de pessoas. Nesse mesmo sentido, foi estreitado o relacionamento com o Bureau of Census americano e o Institut Nacional de Économie et Statistique, da França. Na área administrativa, no processo de seleção de fornecedores, a elaboração de editais para as complexas e inéditas licitações internacionais exigiu o suporte técnico de 
especialistas. Os próprios fornecedores, por sua vez, precisaram ser capacitados conforme as peculiaridades de um projeto fora do cotidiano dos rígidos critérios de precisão e tecnologias envolvidos, para formularem adequadamente suas respectivas propostas comerciais. Nesse sentido, o IBGE acumulou competência para receber e usar novas tecnologias, desenvolvendo capacidade para mudá-las e adequando-as às peculiaridades do contexto ambiental e do projeto no qual seriam aplicadas, gerando inovações (BELL e PAVITT, 1993).

Quanto ao aprendizado necessário aos trabalhos, o IBGE, dentre um universo de um milhão de candidatos, selecionou e treinou 215 mil recenseadores utilizando uma estrutura especialmente montada para dar suporte às operações do CD-2000 no âmbito dos 5.507 municípios do país. Do conjunto de contratados, 650 foram capacitados nos sistemas dos scanners e no programa de identificação de caracteres.

O órgão desenvolveu diferentes modelos de aprendizado (FIGUEIREDO, 2001), conforme descrito no quadro 2. No aspecto tácito e codificado obtido externamente, técnicos visitaram países com expertise tecnológica avançada, foram contratados consultores para a pesquisar a viabilidade de tecnologias alternativas, além de pesquisadores titulados como mestres e doutores, para as definições técnicas dos editais internacionais, sem contar a intensa participação em congressos e fóruns especiais de discussão técnica com segmentos da sociedade. Quanto à aquisição de conhecimentos obtidos internamente, o IBGE desenvolveu melhorias no produto importado de Israel, ao parametrizar as variações de caligrafia dos recenseadores, refinando a capacidade de leitura e interpretação dos sinais. Também construiu protótipos para gerar conhecimento e ajustes no projeto e realizou um prévio e amplo levantamento das demandas da pesquisa social por dados estatísticos, enriquecendo a validade dos questionários de coleta. Os avanços na logística, no desenho de estruturas descentralizadas e nas técnicas de customização de tecnologias de digitalização e de identificação de caracteres, pelos elevados níveis de qualidade alcançados, reduziram os prazos de cinco anos para cinco meses, e foram exportados para os países do Mercosul, para o Chile, Bolívia e, inclusive, para o Bureau of Census, que estuda a viabilidade da sua adoção nos seus próximos planejamentos censitários.

No tocante à socialização de conhecimentos - pelo qual o conhecimento tácito é partilhado através de processos formais e informais de transmissão entre pessoas e grupos -, o órgão promoveu ações de treinamento em massa das equipes de recenseadores; reuniões para troca de experiências bem-sucedidas e análise de falhas, visando uma contínua atualização de conceitos e metodologias; enquanto relatórios sistemáticos detalhavam as etapas do planejamento e execução, os cronogramas e inúmeros gráficos do projeto.

A codificação dos conhecimentos tácitos foi usada de diferentes maneiras: nos procedimentos da prototipagem, nos editais internacionais, na elaboração de manuais e vídeos de treinamento, nas páginas da Internet e na adequação dessa expertise em outros projetos, tais como a digitalização de cartas topográficas e documentos gráficos históricos, gravando-os em CD-ROM com mecanismos de acesso para o público. 



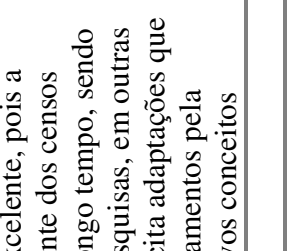

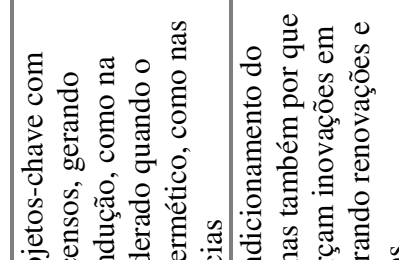

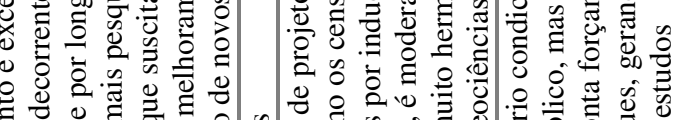

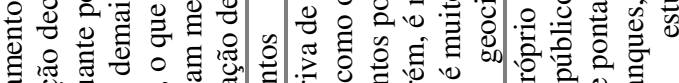

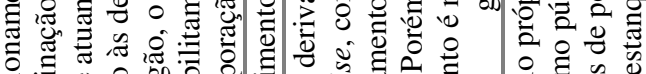

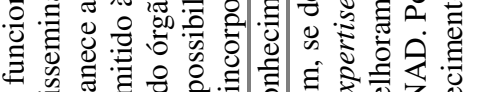

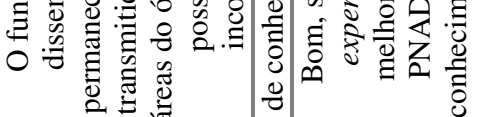

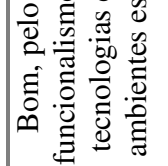

\& 유 :

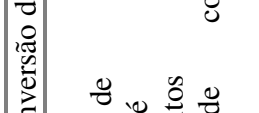

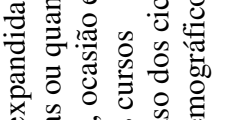

x.

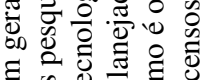

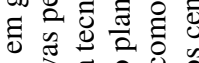

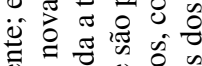

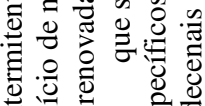

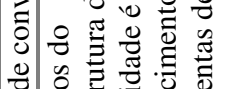

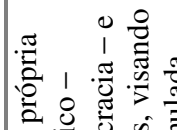

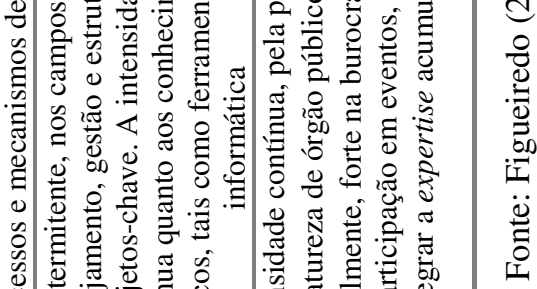

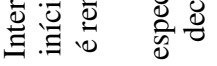

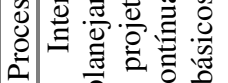

离 语

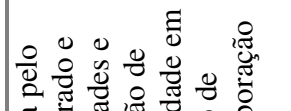

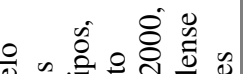

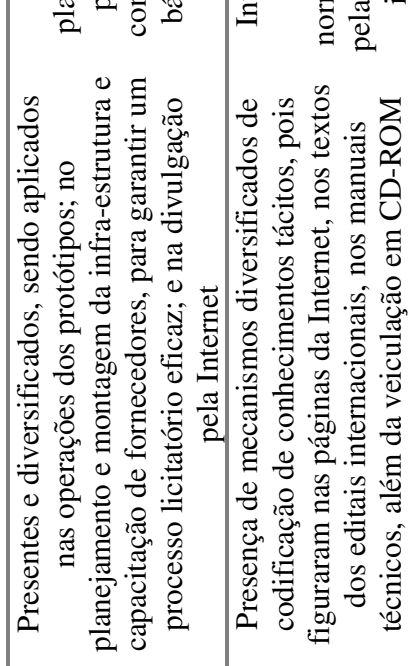

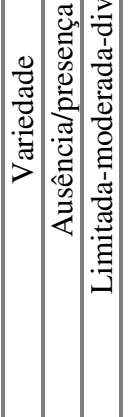

픈

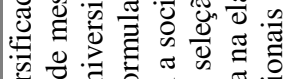

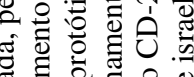

을

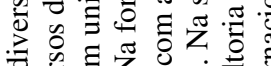

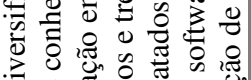

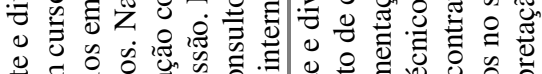

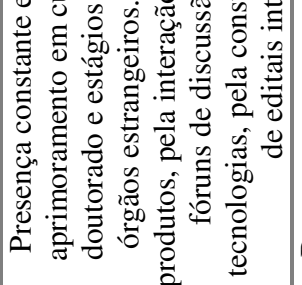

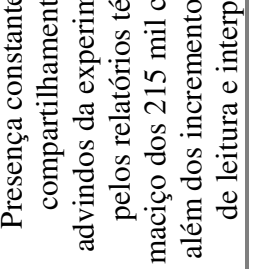

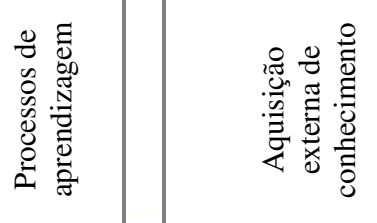

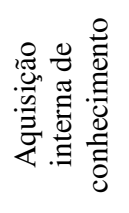

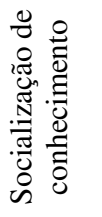

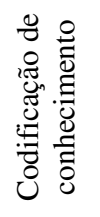

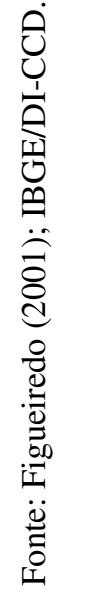


A análise da acumulação tecnológica dos censos, pelo IBGE, segundo a taxonomia de Figueiredo (2001), apresentada na tabela 3, mostra que o órgão demorou 40 anos acumulando experiências e conhecimentos até alcançar um nível de competência que o habilitasse a sair de uma fase de levantamentos inconsistentes para uma estrutura similar à do Bureau of Census. Foi quando montou, nos anos 1980, um parque de informática centralizado no Rio de Janeiro, iniciando um processo de gradativa automação nas rotinas organizacionais, tanto do censo-80 quanto nas demais pesquisas sistemáticas. Porém, remonta a essa época a pioneira experiência de descentralização de estações de minicomputadores para unidades regionais de elevado porte, como a de São Paulo, que processou grande volume de dados daquela região in loco.

No nível 1 da taxonomia, os produtos, gerados com atrasos de até cinco anos, eram formados por volumosos anuários estatísticos, consolidando extensas tabelas de dados sem qualquer informação textual adicional que os tornassem compreensíveis por um público leigo, o que os mantinha acessíveis apenas a uns poucos especialistas.

O órgão demorou 10 anos para chegar aos níveis 1 e 2 da taxonomia, até aplicar inovações tecnológicas também nas pesquisas periódicas, em épocas intermediárias ao ciclo decenal dos censos demográficos, como na Pesquisa Nacional por Amostra de Domicílios (PNAD), que incorporou informações gráficas e um formato mais didático aos produtos finais, visando atingir um público leigo, não-especialista e heterogêneo.

Um relevante salto de inovação, que elevou o órgão ao nível 4 da taxonomia, ocorreu ao longo da década de 1990, abrangendo principalmente as funções das rotinas e equipamentos (FIGUEIREDO, 2001). Nessa época o órgão passou a interagir mais intensamente com a sociedade na escolha das variáveis sociais a serem levantadas e na descentralização da tecnologia pelas unidades regionais, expandindo a capacidade de processamento instalada.

O nível 6, relativo à competência intermediária superior, foi atingido no ano 2000, quando o órgão rompeu com o modelo tradicional de planejamento e gestão de projeto. Foi radicalmente modificado o tipo de tecnologia utilizada até então. O processador main frame, centralizador e de altíssimo custo de manutenção, ${ }^{7}$ foi substituído por plataformas Unix, de processamento distribuído, melhorando assim a pesquisa departamental, pelo desenvolvimento de aplicativos in loco, e também expandindo as configurações de redes de transmissão de dados. Quanto aos produtos, foram desenvolvidos implementos para torná-los mais "amigáveis", adquirindo formato multimídia e disponibilização na página do IBGE na Internet, com tratamento visual e estilo voltados para usuários de todas as idades. A tradicional tecnologia de entrada de dados por digitação manual de questionários de papel - fonte de inúmeros erros humanos e de elevado índice de rejeição - foi substituída pelos scanners e pela interpretação automática dos registros dos questionários, aumentando o grau de eficiência e reduzindo significativamente os prazos de execução, que caíram de cerca de cinco anos para cinco meses, do censo de 1990 para o de 2000.

A estrutura organizacional concebida para o CD-2000, pelo nível de controle e desempenho alcançados, foi exportada não só para outras áreas do próprio IBGE, como também, para outros órgãos públicos nacionais e estrangeiros. Foi, inclusive, objeto de estudos de viabilidade para implantação no ambiente externo que originariamente serviu de referência tecnológica ao IBGE, o Bureau of Census do governo norte-americano.

O nível 6 é imputado ao órgão, na medida em que se estuda a renovação da própria tecnologia utilizada no CD2000, já considerada ultrapassada, levando-se em conta o objetivo das próximas pesquisas estatísticas, que é o processamento puramente digital. Por isso, a tecnologia de scanners e interpretação de caracteres está sendo substituída pela de Palm Top, como no caso da PNAD-2002, desenvolvida especialmente para levantamentos estatísticos, incrementando-se a qualidade a par da redução de custos e de prazos, tendo como meta um "censo on-line".

\footnotetext{
${ }^{7}$ Conferência Nacional de Estatística e Conferência Nacional de Geografia.
} 


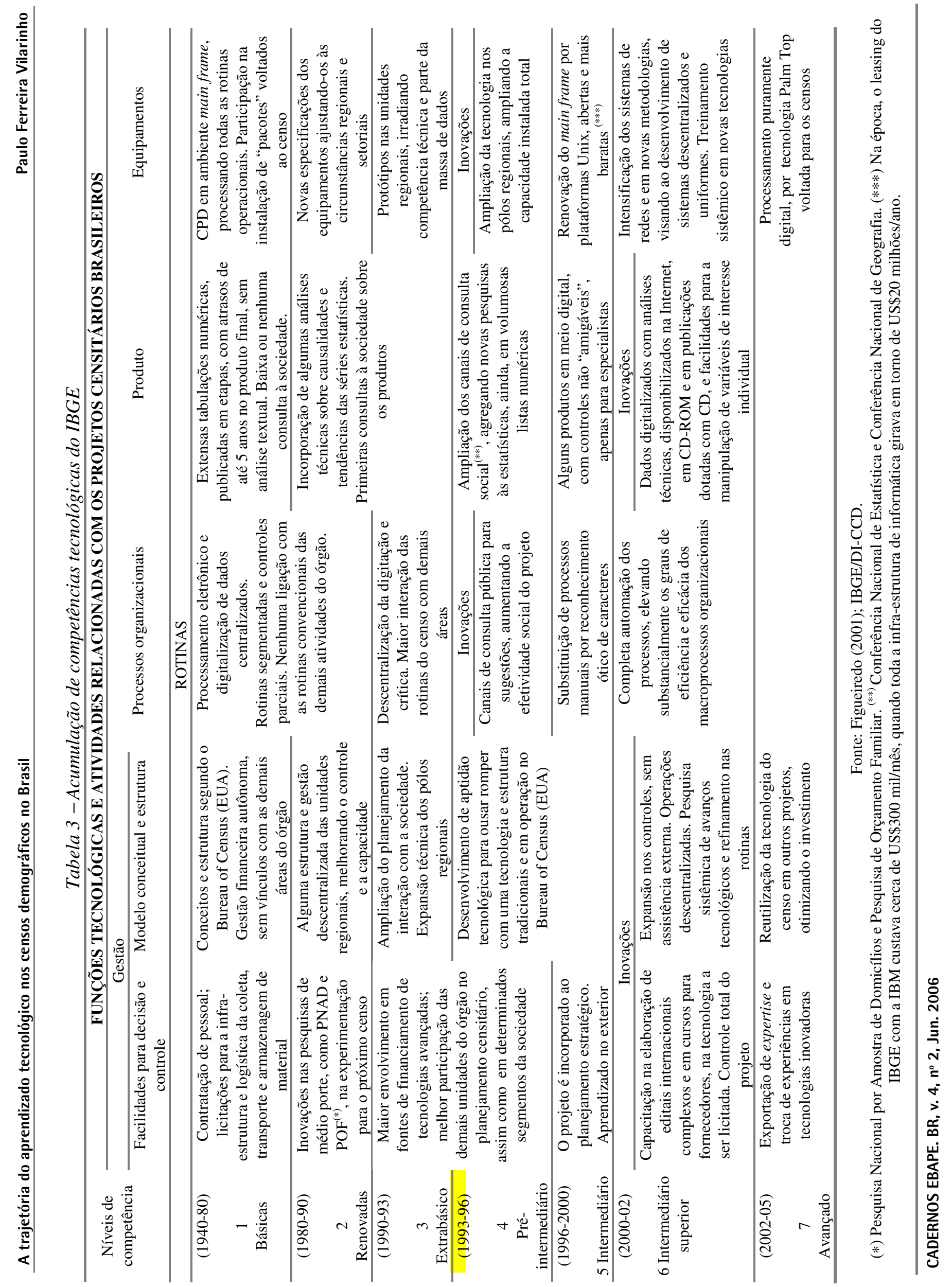




\section{Evolução da intensidade de acumulação de competências tecnológicas}

A acumulação de um determinado nível de competência tecnológica é identificada quando uma organização torna-se capaz de desenvolver uma dada atividade tecnológica que até então não podia (FIGUEIREDO, 2002). Essa análise sinaliza que as funções que mais rapidamente desenvolveram inovações foram a de gestão e equipamentos, demandando 60 e 53 anos, respectivamente, para incorporarem inovações, alcançando, ambas, o nível avançado de competência após 65 anos da criação do órgão. Essas duas funções mantiveram um avanço tecnológico de quase uma década sobre as funções de produto e processos, que atingiram o sexto nível após um período de 65 anos de acumulação tecnológica, como mostrado na tabela 4 e representado no diagrama 1.

Tabela 4

Tempo para acumulação de competências por funções tecnológicas ${ }^{(*)}$

\begin{tabular}{|c|c|c|c|c|c|}
\hline \multirow{2}{*}{\multicolumn{2}{|c|}{ Níveis de competência tecnológica }} & \multicolumn{4}{|c|}{$\begin{array}{c}\text { FUNÇÕES TECNOLÓGICAS RELACIONADAS COM OS } \\
\text { CENSOS DEMOGRÁFICOS }\end{array}$} \\
\hline & & Gestão & Processos & Produtos & Equipamentos \\
\hline 1. Básica & \multirow{4}{*}{ Rotineiras } & 20 & 30 & - & 20 \\
\hline 2. Renovada & & 30 & 40 & 30 & 30 \\
\hline 3. Extrabásica & & 40 & 50 & 40 & 35 \\
\hline 4. Pré-intermediário & & 50 & 60 & 50 & 40 \\
\hline 5. Intermediário & \multirow{3}{*}{ Inovações } & 60 & 62 & 56 & 53 \\
\hline 6. Intermediário superior & & 62 & 65 & 62 & 60 \\
\hline 7. Avançado & & 65 & - & - & 65 \\
\hline
\end{tabular}

Fonte: Figueiredo (2001, p.226)

(*) Escala de tempo em anos, compreendendo o período 1940-2005.

Segundo a pesquisa, embora o IBGE tenha permanecido estagnado tecnologicamente por quase 30 anos, a partir dos anos 1990, deu início à formulação de inúmeros objetivos estratégicos em estreita associação com processos de inovação tecnológica de alta performance, posto que o órgão não perseverou numa estratégia única, mas num conjunto articulado de estratégias que resultaram, após 60 anos, na flexibilidade e performance dos processos e qualidade dos produtos gerados, além da rapidez no seu lançamento ante a sociedade (ROTHWELL, 1994). Portanto, desenvolvendo competência para renovar conhecimentos externos e gerar novas tecnologias (LEONARD-BARTON, 1998), o órgão logrou equilibrar a contínua assimetria com o Bureau of Census quanto à performance operacional e à qualidade de produtos, melhorando, desse modo, a sua classificação em termos de distanciamento da curva da fronteira tecnológica. Nesse sentido, o IBGE inverteu, por meio de diferentes processos de aprendizagem, o clássico conceito de ineficiência dos órgãos de Estado, distinguindo-se de outras organizações, públicas e privadas, produtoras de dados estatísticos, e facilitando ao máximo a transformação de conhecimentos científicos e tecnológicos em produtos de informação exploráveis pela sociedade (DOSI, 1998).

Como mostrado no quadro 2, a aquisição e a socialização de conhecimentos não é homogênea: a aquisição externa (via de regra, nos EUA), em cursos stricto sensu, em estágios no Bureau of Census ou, ainda, em congressos científicos costuma ser disseminada de modo intenso apenas nas áreas técnicas e moderadamente nas unidades com aplicações fora da órbita do censo, criando ilhas de especialização. Por outro lado, a aquisição e a interação interna é contínua e abrangente no campo da informática. A socialização e codificação é diversificada: desde textos de editais internacionais, manuais, cursos e produção de mídias na Internet, principalmente com o CD-2000 - cuja expertise intrínseca das suas rotinas operacionais aos poucos se integram, por um processo osmótico -, aos projetos de outras áreas, como visualizado no diagrama 2. 
Diagrama 1 - Evolução da trajetória de acumulação tecnológica no IBGE

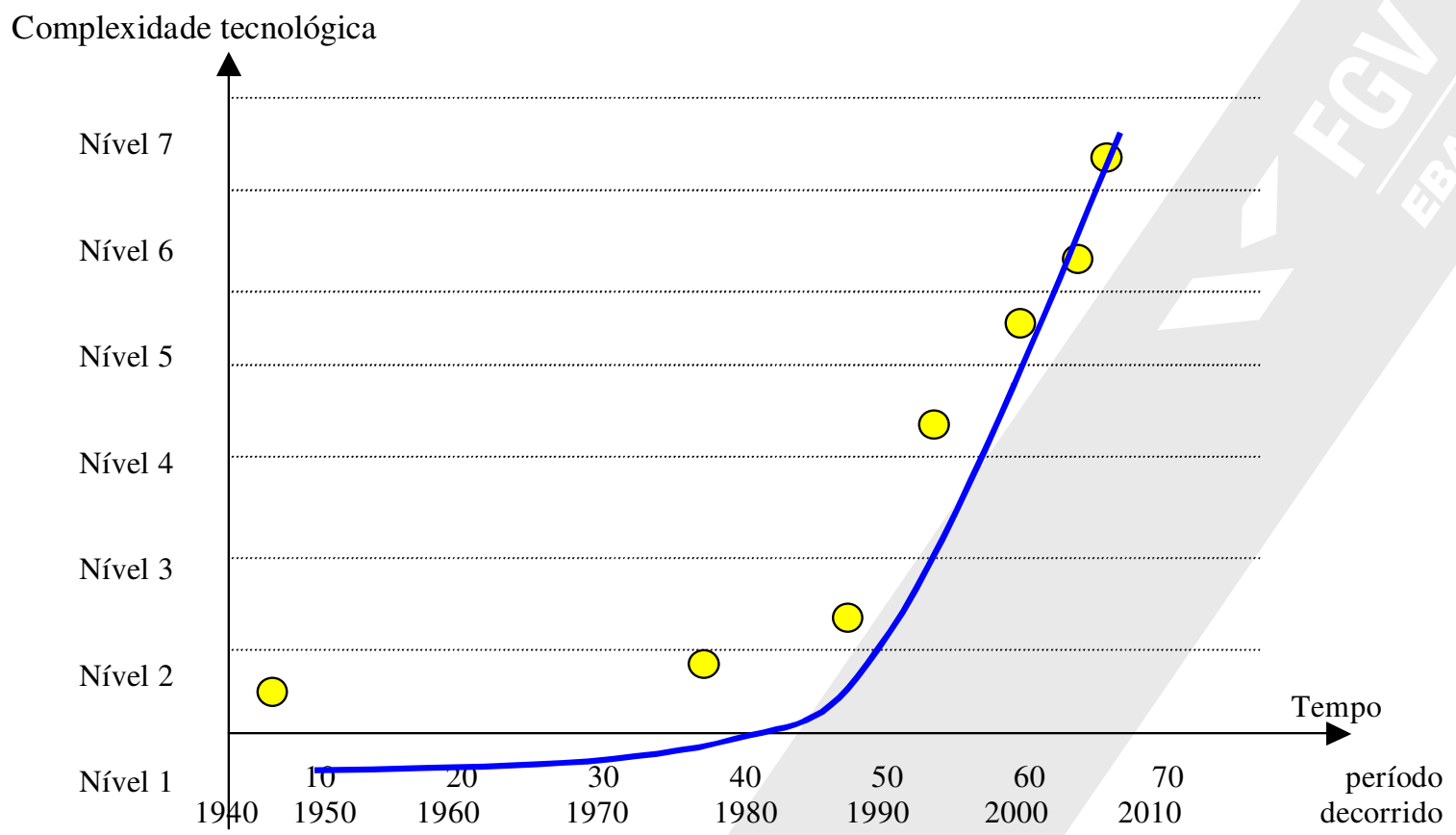

Diagrama 2 - Características dos processos de conhecimento do IBGE

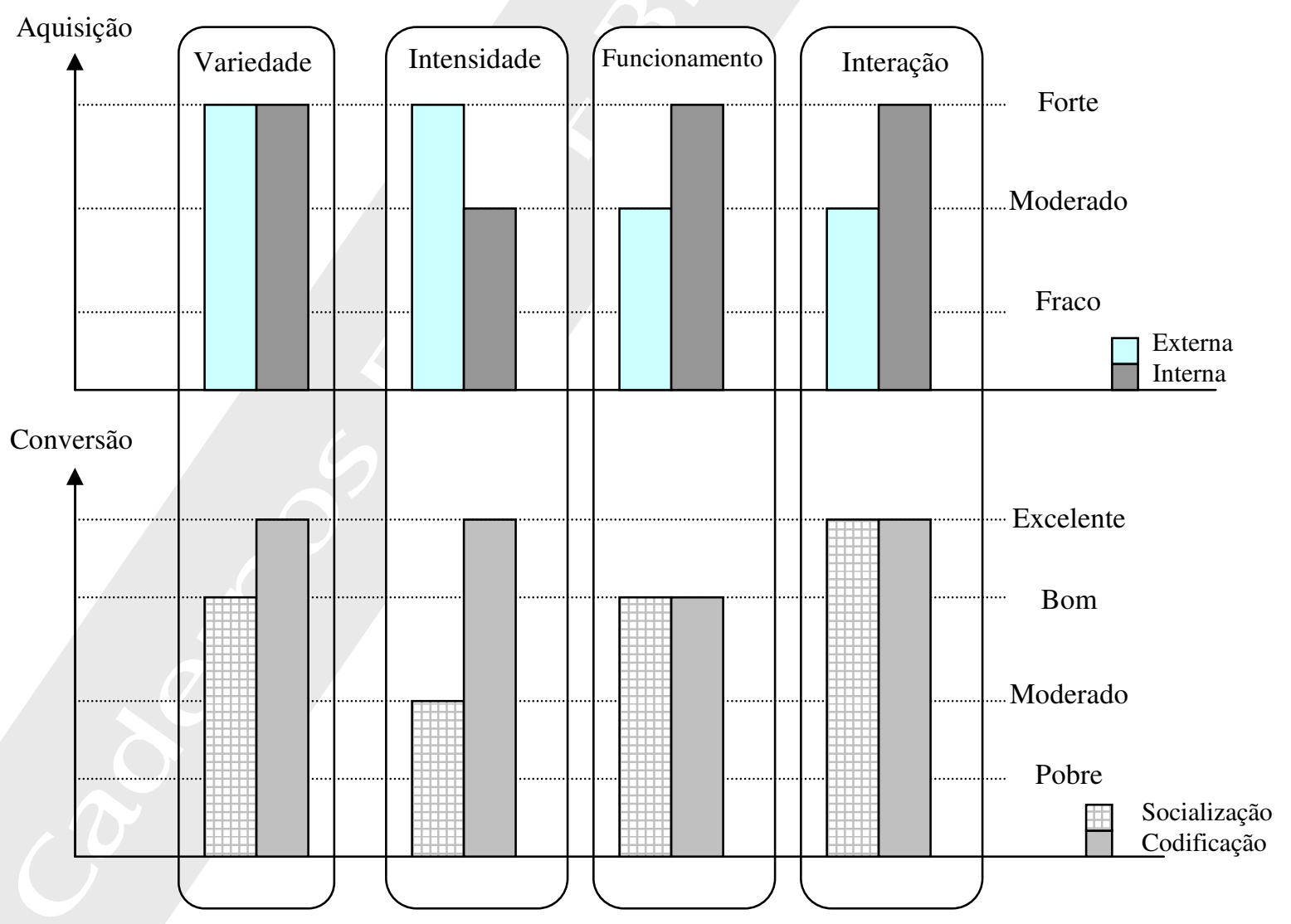




\section{Conclusão}

A pesquisa demonstrou que o restabelecimento da democracia no Brasil, em 1988, quebrou o hermetismo e a autonomia técnico-administrativa em que permanecera o IBGE por 40 anos, desde o governo Vargas, quando foi instituído para prover informações visando à solidificação de um Estado forte e centralizado, desprezando as iniciativas e a cultura das unidades da federação, as quais foram mantidas num isolamento cultural e político. $\mathrm{O}$ ambiente político autoritário prolongado contribuiu para o isolamento do órgão por quase meio século, mantendo-o estagnado e refratário à renovação de sua tecnologia e à capacitação do seu corpo técnico. Isso acabou gerando produtos estatísticos de baixa complexidade, em forma de listas numéricas maçantes, sistematicamente enviadas para outras áreas do governo, e praticamente incompreensíveis para o grande público.

Não é por acaso que o salto de qualidade tecnológica do órgão ocorreu a partir da década de 1990, quando o IBGE se abriu à sociedade e aceitou críticas quanto à natureza do seu papel para os brasileiros. A partir de então, reformulou valores institucionais e renovou seu corpo técnico, por meio do qual incorporou novos conhecimentos, tácitos e teóricos, pois muitos eram egressos do meio acadêmico, trazendo expertise pessoal para dentro do órgão no campo da informática, no tratamento de estatísticas e nas geociências.

A geração interna de conhecimentos, até então circular, tornou-se espiralada quando as pessoas foram chamadas a agregar seu conhecimento e evoluir junto com a organização, gerando aptidões para compreender e acompanhar o processo evolutivo da tecnologia, extremamente acelerado nos anos 1990. Quando a estrutura tecnológica foi descentralizada, incorporando as atividades dos técnicos residentes no interior do país - capacitando-os numa tecnologia de médio porte -, estes rapidamente produziram inovações tanto nas rotinas quanto nas especificações metodológicas de desenvolvimento de sistemas, como a demonstrar que "existe vida inteligente no interior do Brasil".

A uniformização do nível de competência tecnológica individual no âmbito do órgão permitiu expandir a capacidade operacional do parque pela descentralização dos processos de produção para as unidades regionais, que desenvolveram melhoramentos incorporados no processo como um todo. Assim, foi desenvolvido um ambiente de controle de qualidade e de inovações espontâneo e transparente, cujos efeitos foram sentidos no resultado final. A trajetória tecnológica do IBGE, no bojo dos censos demográficos, evidencia, na prática, que o efetivo patrimônio tecnológico de uma organização é o conhecimento dos seus funcionários em contínua interação.

Por outro lado, uma vez concluído o CD-2000 e substituindo-se a tecnologia empregada por outra a ser utilizada doravante, fica a dúvida sobre o destino dos 31 scanners, 10 gravadores de CD, das 1.476 estações de trabalho, dos 51 servidores de rede e do software de interpretação de caracteres - um investimento que consumiu US\$130 milhões -, que podem ser encaixotados e armazenados num galpão na reserva do Roncador, amplo repositório de muitas outras tecnologias ultrapassadas.

Por esta razão, o estudo sugere que processos de aprendizagem tecnológica devem se estender além das fronteiras do projeto que deu azo à sua aquisição e aprimoramento, devendo-se pesquisar adaptações em outros campos da ciência, visando esgotar por completo a sua capacidade operacional, gerando os chamados projetos duais que reciclam conhecimentos recém-ultrapassados, para um dado contexto, em verdadeiras inovações, em outros ambientes. 


\section{Referências}

BELL, M.; PAVITT, K.. Technological accumulation and industrial growth: contrasts between developed and developing countries. Industrial and Corporate Change, v.2, n.2, p.157-211, 1993.

DOSI, G. The nature of the innovative process. In: DOSI, G., FREEMAN, R., NELSON, G.; SILVERBERG, G., SOETE, L. (eds), Technical Change and Economic Theory. London: Pinter Publishers, 1988.

FIGUEIREDO, P. Technological learning and competitive performance. Cheltenham, UK: Edward Elgar, 2001.

Does technological learning pay off? Inter-firm differences in technological capability-accumulation paths and operational performance improvement. Research Policy, n.31, p.73-94, 2002.

HIPPÓLITO, L. Censos demográficos: só 50 anos de idade. Rio de Janeiro, 1990 (mimeo).

LALL, S. Technological capabilities and industrialization. World Development, v.20, n.2, p.165-182, 1992.

LEONARD-BARTON, D. Nascentes do saber: criando e sustentando as fontes de inovação. Rio de Janeiro: Fundação Getulio Vargas, 1998.

NELSON, R. The role of firm differences in an evolutionary theory of technical advance. Science and Public Policy, v.18, n.6, 1991.

PAVIT, K. Preface. In: ROSENBERG, N., FRISCHTAK, C. International technology transfer: concepts, measurements and comparisons. London: Praeger Publishers, 1985.

PENHA, E. A. A criação do IBGE no contexto da centralização política do Estado Novo. Rio de Janeiro: IBGE, 1993. (Documentos para divulgação. Memória Institucional - 4).

ROTHWELL, R. Industrial innovation: success, strategy, trends. In: DODGSON, M.; ROTHWELL, R. (Ed.). The handbook of industrial innovation. Cheltenham, UK: Edward Elgar, 1994. p. 33-53.

TEECE, D., PISANO, G., SHUEN, A.. Dynamic capabilities and strategic management. California: University of California at Berkeley, 1990. Mimeografado.

WINTER, S.. On Coase, competence and the corporation. Journal of Law, Economics and Organization, v.4, n.1, 1988. 